\title{
Seasonal and Vertical Variability of Currents Energy in the Sub-Mesoscale Range on the Black Sea Shelf and in Its Central Part
}

\author{
O. S. Puzina ${ }^{\bowtie}$, A. A. Kubryakov, A. I. Mizyuk \\ Marine Hydrophysical Institute of RAS, Sevastopol, Russian Federation \\ 凶oksana_puzina@mhi-ras.ru
}

Purpose. The study is aimed at investigating seasonal variability and vertical distribution of the submesoscale currents energy (scales $L=1 \ldots 10 \mathrm{~km}, T=1 \ldots 10$ days) in the deep and shelf zones of the Black Sea.

Methods and Results. The study is based on the spectral analysis of the results obtained from the $N E M O$ model numerical calculations performed with high spatial resolution $1 \mathrm{~km}$. The analysis shows that the seasonal variability of the submesoscale energy is significantly different in deep and shelf zones of the basin. At the same time, in both regions, seasonal variation of energy of the sub-mesoscale currents with scales $\mathrm{L}<10 \mathrm{rm}\left(E_{\mathrm{sp}}\right)$ is in good agreement with that of the density fluctuations on the same scales. In the central part of the sea, the high values of $E_{\text {sp }}$ are concentrated in the upper mixed layer throughout the whole year. The $E_{\mathrm{sp}}$ peak is observed in winter at the depths $0-40 \mathrm{~m}$, which indicates the important role of baroclinic instability induced by the inhomogeneous distribution of the mixed layer depth (MLD) in the generation of submesoscale processes. At the same time, in February in the central part of the northwestern shelf, an absolute minimum of $\left(E_{\mathrm{sp}}\right)$ is observed. This minimum is caused by the complete mixing and barotropization of the water column. The $E_{\mathrm{sp}}$ maximum values are observed in the shelf in September - October. This is related to the intensification of the brackish water transport from the river mouths by mesoscale eddies. In the autumn period high values of $E_{\mathrm{sp}}$ in the shelf and deep part of the basin are observed in the deeper layer, compare to summer months .Variability of the $E_{\text {sp }}$ vertical distribution coincides to the time variation of MLD. Variability of the submesoscale energy is of a pulsating character with the short-term intensifications and weakenings. Such variability is significantly related to the passing of the mesoscale fronts and the cross-shelf water transport caused by the eddies and upwellings, which lead to the increase of the baroclinic instability.

Conclusions. Analysis of the seasonal and vertical variability of the submesoscale currents in the Black Sea deep and shelf zones evidences about the decisive role of the baroclinic instability triggered mainly by the heterogeneity of MLD on their dynamics.

Keywords: Black Sea, spectral analysis, sub-mesoscale currents, sub-mesoscale eddies, baroclinic instability, numerical modeling, NEMO

Acknowledgments: Seasonal variability of the submesoscale fluctuations was studied with support of the RFBR grant No. 19-05-00479.

For citation: Puzina, O.S., Kubryakov, A.A. and Mizyuk, A.I., 2021. Seasonal and Vertical Variability of Currents Energy in the Sub-Mesoscale Range on the Black Sea Shelf and in Its Central Part. Physical Oceanography, [e-journal] 28(1), pp. 37-51. doi:10.22449/1573-160X-2021-1-37-51.

DOI: $10.22449 / 1573-160 X-2021-1-37-51$

(C) O. S. Puzina, A. A. Kubryakov, A. I. Mizyuk, 2021

(C) Physical Oceanography, 2021

\section{Introduction}

Submesoscale currents at $L=1 \ldots .10 \mathrm{~km}, \quad T=1 \ldots 10$ day ${ }^{1}$ scales are an intermediate link between the mesoscale and small-scale currents and play a crucial

\footnotetext{
${ }^{1}$ Kamenkovich, V.M., Koshlyakov, M.N. and Monin, A.S., 1986. Sinoptic Eddies in the Ocean. D. Reidel Publishing Company: Dordrecht, Holland, 443 p. doi:10.1007/978-94-009-4502-9 
role in the cascade and dissipation of the ocean energy. Submesoscale dynamics has a significant effect the vertical exchange and ocean stratification [2-5]. In the coastal zone the submesoscale dynamics also significantly impact on the horizontal exchange, contributing to the cross-shelf transport of organic and inorganic suspended matter [6-9], mixing of waters, for example, at the fronts of river plumes or at the boundary of upwellings [10-11].

The main information on the Black Sea submesoscale eddies was obtained from the satellite optical and radar data. The works [12-14] describe the geometric characteristics of such eddies, the statistics of their observations in some areas of the sea, and their relationship with the topography features. In [15], on the basis of in-situ measurements, it was shown that the velocities in submesoscale eddies with a radius of 3-5 km can reach $0.25-0.5 \mathrm{~m} / \mathrm{s}$ values, which indicates high Rossby numbers in these formations. A description of the mechanisms of submesoscale eddies generation and their analysis using satellite data and laboratory modeling in the Black Sea are given in [16]. The authors of this work demonstrate that an important mechanism for the eddy formation is the barotropic instability caused by a velocity shear at the fronts of mesoscale anticyclones when interacting with topographic features and the intense wind effect.

The development of numerical modeling methods provides the detailed study of the generation mechanisms of submesoscale currents and the features of their spatial-temporal variability in different ocean regions $[17,18]$. The model data in [10-19] allow one to obtain information on the seasonal variability of submesoscale currents based on spectral analysis. In particular, such studies have shown that the seasonal maximum of the submesoscale current energy in the Atlantic Ocean deep-water part is observed in winter [19]. The formation of submesoscale eddies at this time is observed at the lower boundary of the upper mixed layer (ML) and is associated with horizontal density gradients arising from the inhomogeneity of its depth [3, 17, 20-21].

In the Black Sea, a very limited number of works have been devoted to studies of sub-mesoscale dynamics based on numerical modeling data. In [22-24], the model capabilities to reconstruct submesoscale eddies in different parts of the basin are demonstrated. Analysis of the energetics of mesoscale and submesoscale eddies in [22] showed the important role of buoyancy forces in the formation of these dynamic structures.

In this work, based on the spectral analysis of the velocity modulus according to the calculations of high-resolution NEMO model $(1 \mathrm{~km})$, for the first time, the seasonal variability and vertical distribution of energy of submesoscale currents $\left(E_{\mathrm{sp}}\right)$ in the Black Sea are studied. In addition, a comparative analysis of these characteristics in the open and shelf parts of the sea is carried out. This makes it possible to reveal significant differences in the mechanisms of the sub-mesoscale water dynamics formation in the considered areas of the basin.

\section{Data and methods}

Regional configuration of $N E M O$ model [25] with high spatial resolution, which provides a reconstruction of meso- and submesoscale variability of hydrophysical fields in the Black Sea basin [26], is applied in the work. The computational domain is a quasi-regular grid covering a cascade of basins of 
the Marmara, Black and Azov Seas with $1 / 96^{\circ}$ step in latitude and $1 / 69^{\circ}$ in longitude. This corresponds to approximately $1.157 \mathrm{~km}$ in the meridian direction. Along the parallel, the step changes uniformly from $1100 \mathrm{~m}$ in the north to $1230 \mathrm{~m}$ in the south. The bottom topography was constructed using the bathymetric data from EMODnet portal (URL: http://www.emodnet-bathymetry.eu). In order to obtain adequate values of discharge through the Bosphorus, the "half-enclosed cell" technique was used [25] to achieve a transverse dimension in the strait of $1000 \mathrm{~m}$. The calculation was carried out for 2008-2009 period.

The hydrodynamic block of the model is based on a system of primitive equations [25]. The TVD scheme [27] is used for the nonlinear terms in the transport - diffusion equations of heat and salt. Time discretization is carried out using a modified "leapfrog" scheme [27]. The z-coordinate is used vertically with a fractional step.

The parameterization of vertical turbulent mixing was performed using $k-\varepsilon$ model [28]. Horizontal exchange is described by a biharmonic operator with the coefficients of viscosity $\left(-4 \cdot 10^{7} \mathrm{~m}^{4} / \mathrm{s}\right)$ and heat and salt diffusion $\left(-8 \cdot 10^{6} \mathrm{~m}^{4} / \mathrm{s}\right)$. UNESCO formula is used as the equation of state. In order to calculate the sea level, the time splitting scheme is used. This means that at each step of the so-called slow mode $(1 \mathrm{~min})$, the vertically-averaged equations of motion are numerically integrated with a step of the "fast" mode (4 s).

In the numerical integration of the system of equations on rigid lateral boundaries for the tangential velocity component in the equations of motion, slip conditions and the equality of the normal velocity component to zero are set. At the bottom, nonlinear friction for the horizontal velocity components is set, and the vertical velocity component is set to be equal to zero. In the equations of transport - diffusion of heat (salt) at the lateral boundaries and the bottom, the condition of the absence of fluxes is set.

For the boundary conditions on the surface, in this work we use the fields of temperature and air humidity at $2 \mathrm{~m}$ level, the wind velocity horizontal component at $10 \mathrm{~m}$ level, the fluxes of descending long-wave and short-wave radiation, precipitation in the liquid and solid phases from the global atmospheric reanalysis of the latest generation $E R A 5^{2}$. This product has $1 / 4^{\circ}$ spatial resolution. The temporal resolution is 1 hour.

The temperature and salinity fields provided by the Black Sea Marine Forecast Center (http://mis.bsmfc.net:8080/thredds/catalog.html) were used as the initial conditions for the Black Sea. Initial conditions for the Sea of Azov were prepared using an objective analysis of field observations provided by CMEMS and SeaDataNet oceanographic project database (https://www.seadatanet.org/). For the Sea of Marmara, the initial conditions are taken from the global reanalysis of CMEMS service. A more detailed description of the experiment is presented in [26].

\footnotetext{
${ }^{2}$ ECMWF. Copernicus Climate Change Service Climate Data Store. ERA5: Fifth Generation of ECMWF Atmospheric Reanalyses of the Global Climate. 2017. [on-line] Available at: https://cds.climate.copernicus.eu/cdsapp\#!/home [Accessed: 25 January 2021].
} 
An example of vorticity and current velocity maps calculated by the model is shown in Fig. 1. These maps clearly show dynamic structures of various scales: numerous submesoscale eddies in the center of the sea, a large number of small eddies on the northwestern shelf (NWS) of the basin, as well as larger anticyclones to the right of the Rim Current (RC) in the continental slope region of basin. For the analysis in this work, we selected areas in the deep-water part (42.5-44 $\mathrm{N}$, $\left.31-38.8^{\circ} \mathrm{E}\right)$ and in the center of the NWS (44.75-45.8 $\left.\mathrm{N}, 31-32.5^{\circ} \mathrm{E}\right)$. The areas were selected in such a way that the bottom depth was practically uniform.

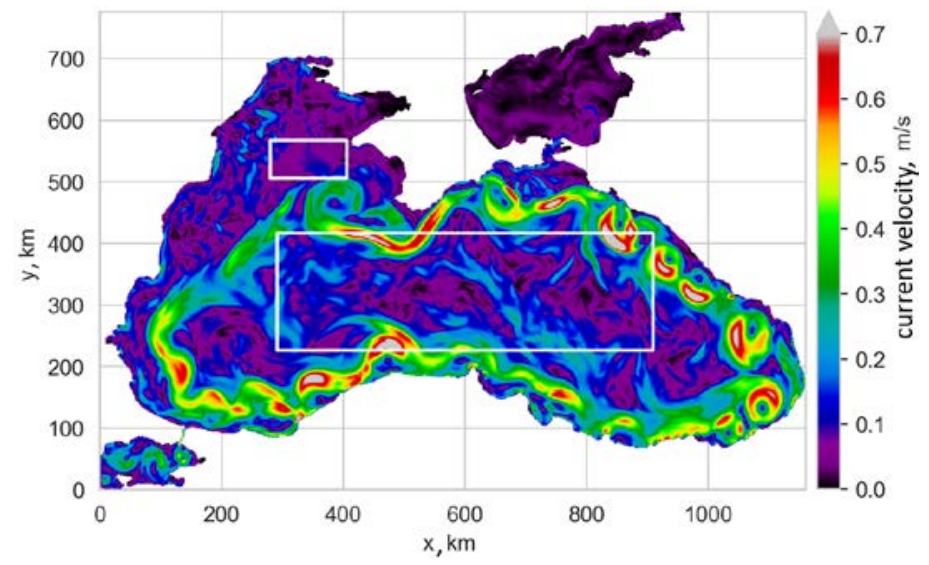

$a$

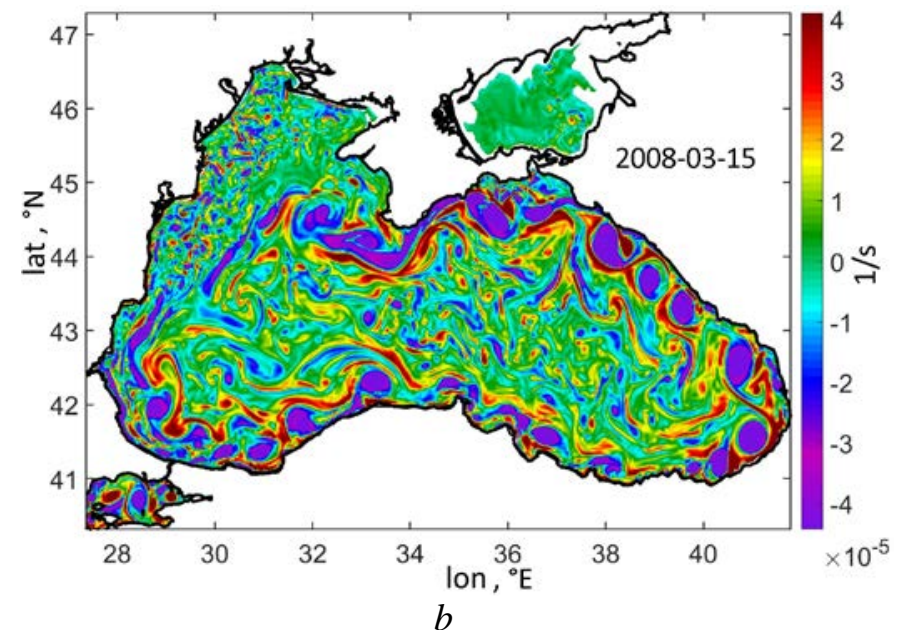

F i g. 1. Example of the field of the currents velocity $(a)$ and vorticity $(b)$ module on the surface on March 15, 2008. The rectangles show the areas under study: large rectangle - the sea central part; small one - the shelf area

We use spectral analysis to calculate the two-dimensional spatial spectra of the current energy $\mathrm{E}\left(\mathrm{k}_{\mathrm{x}}, \mathrm{k}_{\mathrm{y}}\right)$, where $\mathrm{k}_{\mathrm{x}}$ and $\mathrm{k}_{\mathrm{y}}$ are the wave numbers. The calculated characteristics were used to determine the isotropic one-dimensional spectrum $\mathrm{E}(\mathrm{k})$, where $k=\sqrt{k_{x}^{2}+\mathrm{k}_{y}^{2}}$. 


\section{Results}

\subsection{Spectral characteristics of current velocity in the Black Sea}

The spatial spectra of the current velocity and density in the selected areas are represented in Fig. 2. The energy of oscillations in the sea central part is on average higher than in the shelf one. An exception is the limited region of small scales $(3-5 \mathrm{~km})$, where a rather pronounced peak in the energy of currents is observed, which suggests an increase in submesoscale processes in the shelf. The density spectrum (Fig. 2, $b$ ) has a similar form - with a pronounced peak on 3-5 km scales - which indicates the baroclinic nature of the observed velocity fluctuations. The values of the energy of density fluctuations in the central and shelf regions on large scales are comparable, in contrast to the values of the energy of fluctuations in the current velocity in these regions.
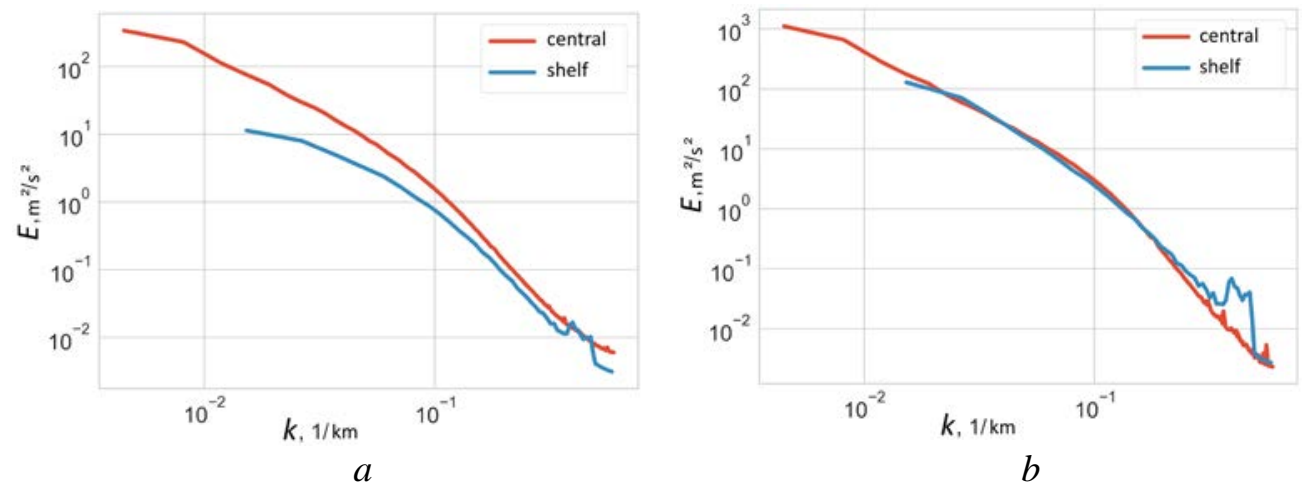

F i g. 2. Mean spatial spectrum of: $a$ - velocity, $b$ - density at the $6.5 \mathrm{~m}$ depth in the central (red line) and shelf (blue line) parts of the Black Sea
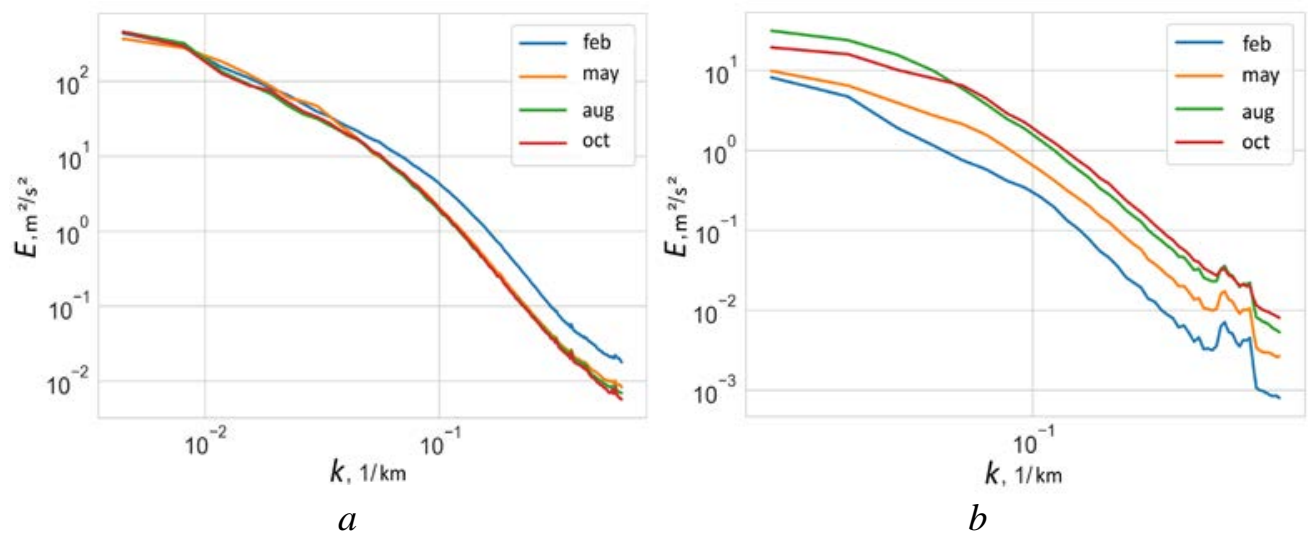

F i g. 3. Spatial spectra of the current velocities at $6.5 \mathrm{~m}$ depth in the central $(a)$ and shelf $(b)$ parts of the Black Sea for different seasons

An analysis of spatial spectra in different seasons showed that the shape of velocity spectra in the central part is almost the same throughout the year, except for the winter months (Fig. 3, a). In winter, the energy on small spatial scales $(L<20 \mathrm{~km})$ increases significantly, by $2-3$ times compared to other seasons. For the shelf part, seasonal differences are more pronounced (Fig. 3, $b$ ). At the same PHYSICAL OCEANOGRAPHY VOL. 28 ISS. 1 (2021) 
time, here, in contrast to the central part, in the winter period a decrease in energy at all scales takes place, and its maximum is observed in the late summer and autumn periods. At this time, the energy of the currents exceeds the winter energy by more than an order of magnitude. Note that in the summer period (green line) the energy is the maximum at large scales, which may be associated with the intensification of mesoscale eddy dynamics in summer in the Black Sea $[29,30]$. At the same time, on smaller scales $(L<15 \mathrm{~km})$, the energy is maximum in the autumn period.

The main feature of the spectral energy vertical distribution for both selected regions is its decrease with depth (Fig. 4). In the region of wavenumbers $k>0.1$ or $L<10 \mathrm{~km}$, which corresponds to the definition of submesoscale in this work, the energy is maximum in the upper active layer $(0-50 \mathrm{~m})$ in the center of the sea (Fig. 4, a). Below the active layer at 50-200m depth, the energy drops by more than an order of magnitude and by more than two orders of magnitude in the underlying layers. For the shelf area, an increase in the upper layer $(0-25 \mathrm{~m})$ and a gradual decrease in the bottom layers (Fig. 4, $b$ ) are also noticeable.

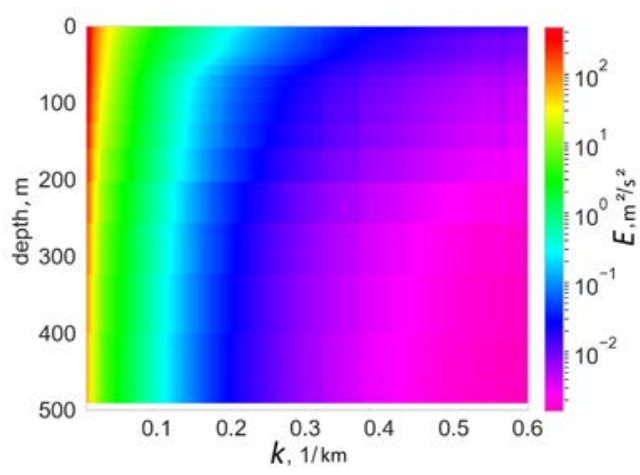

$a$

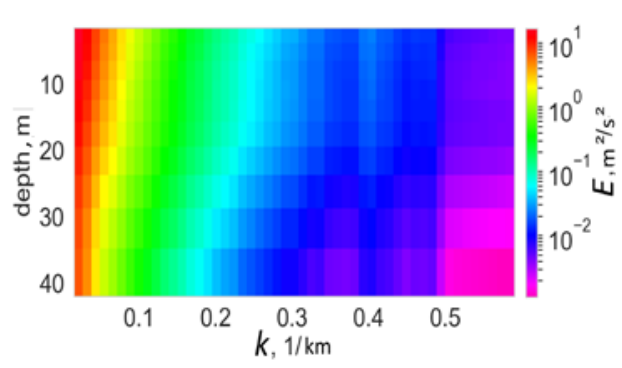

$b$

F i g. 4. Vertical diagram of velocity spectral energy $E, \mathrm{~m}^{2} / \mathrm{s}^{2}$, averaged for the whole calculation period in the central $(a)$ and shelf $(b)$ parts of the Black Sea

For illustrating seasonal changes in the distribution of the energy spectra over depth, Fig. 4 shows diagrams of the logarithm of energy anomaly, calculated as $R=\langle\log (E)-\log (\langle E\rangle)>$, where $\langle E\rangle$ is the spectral energy averaged over the entire calculation period. In January, in the Black Sea central part at submesoscales ( $k>0.11 / \mathrm{km}$ ), positive $R$ values are noted in $0-60 \mathrm{~m}$ upper layer and in deep layers below $200 \mathrm{~m}$ level/horizon. The maximum increase in energy is noted in 0-60 m layer, which corresponds to the ML lower boundary, as well as in the surface layer. At the same time, in $80-200 \mathrm{~m} R$ values are negative for the smallest scales $(L \leq 5 \mathrm{~km})$, i.e. a weakening of submesoscale dynamics takes place. In June (Fig. $5, b$ ), the picture is opposite: in 0-40 m layer, the energy of submesoscale processes weakens, and at $50-250 \mathrm{~m}$ depths it increases. On the mesoscales the energy also increases up to 300-400 m depths. In October (Fig. 5, $c$ ), a narrow region of positive $R$ values and energy increase are noted in the lower part of the seasonal thermocline at 20-30 m depths. At the same time, below the thermocline, energy decreases. During this period, in the deeper layers the energy is more than in winter but less than in summer. 


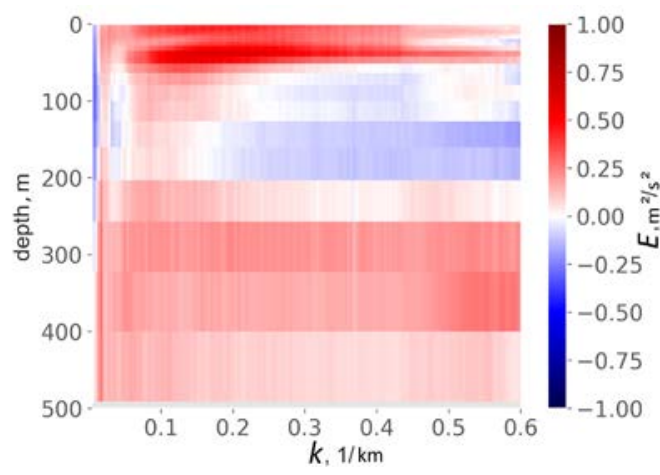

$a$

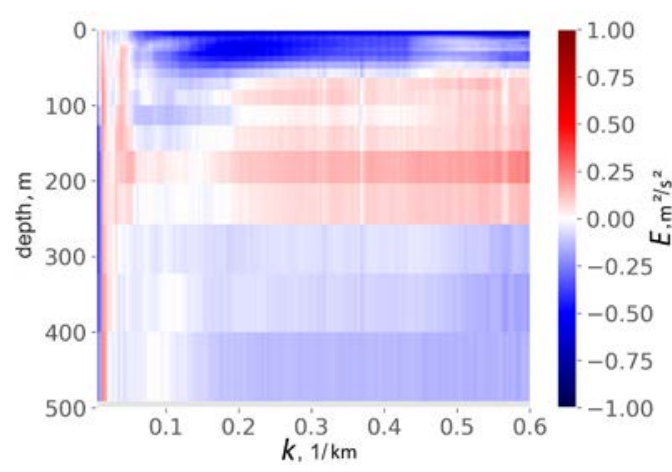

C

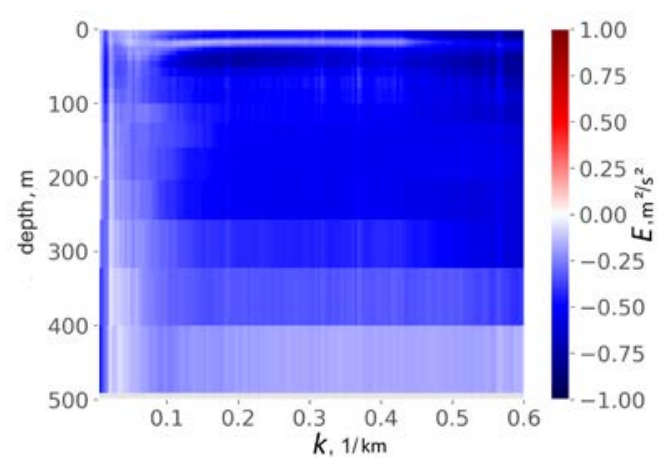

$e$

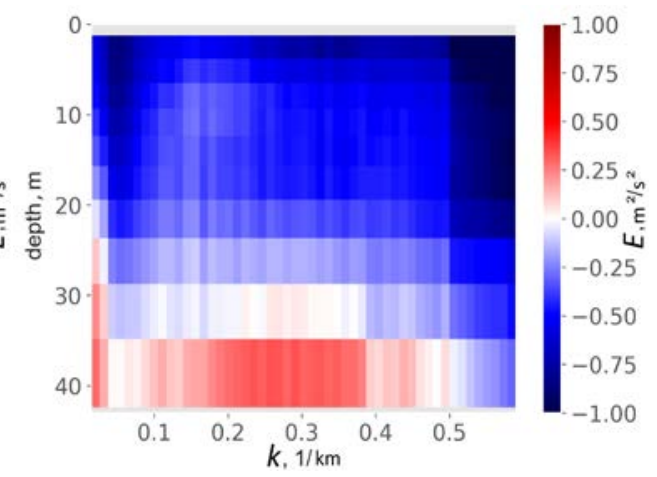

$b$

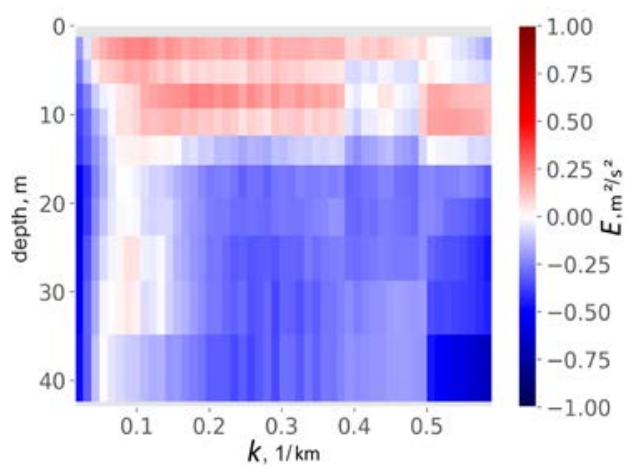

$d$

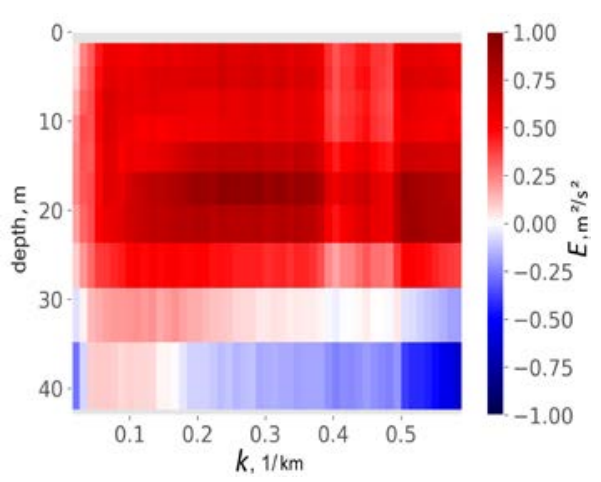

$f$

F i g. 5. Anomaly of the logarithm of spectral energy $R$ against its average distribution for January $(a)$, June $(c)$ and October $(e)$ in the Black Sea central part; for January $(b)$, June $(d)$ and October $(f)$ in the sea shelf part

In the shelf area, the distribution $R$ significantly differs. In winter, a significant energy decrease is observed in the upper layer both at large and at the smallest scales (Fig. 5, b). At the same time, the energy of currents increases in the lower bottom layer $(30-40 \mathrm{~m})$. In summer, the opposite situation is observed - 
the oscillation energy increases in the upper quasi-uniform layer and the transition layer $(0-15 \mathrm{~m})$, decreases in the bottom part for the range $L<10 \mathrm{~km}$ and $L>20 \mathrm{~km}$, and on the Rossby radius scales $(10-20 \mathrm{~km})$ remains constant or increases slightly (Fig. 5, $d$ ). In autumn period, the energy maximum deepens along with the MLD to 10-25 m depths (Fig. 5, e). A significant increase in energy is noted in the entire seasonal thermocline ( $0-25 \mathrm{~m}$ layer). In the underlying layers in the autumn season, as in summer, the energy is much lower than in January.

3.2. Seasonal and vertical variability of the energy of submesoscale currents in the Black Sea

The presented diagrams indicate significant seasonal and vertical variability of the intensity of submesoscale currents in the Black Sea. In order to study this variability, the obtained spectra were averaged for the wavelength range $L=1 \ldots 10 \mathrm{~km}: E_{\mathrm{sp}}=E(L<10 \mathrm{~km})$.

Note that for the sea central part, the value $L=10 \mathrm{~km}$ is less than the Rossby deformation radius $R d$, equal to $25 \mathrm{~km}$ [31]. At the same time, in the shallow shelf areas, the Rossby baroclinic radius may be slightly lower than the selected limiting $10 \mathrm{~km}$ value. However, as can be seen from Fig. 5, the patterns of seasonal variability of spectral energy within $L=2 \ldots 10 \mathrm{~km}$ range are similar, which indicates the acceptability of the selection of this criterion for the analysis of submesoscale variability on the shelf.

Seasonal variability of $E_{\mathrm{sp}}$ at the upper horizon of the model $z=1.2 \mathrm{~m}$ and at $40 \mathrm{~m}$ depth is shown in Fig. 6, $a$. We note the pronounced differences in the seasonal variation of submesoscale processes on the shelf and in the center of the basin. Submesoscale currents intensify in winter in the center of the sea and in late summer - autumn at the shelf. At the same time, on the surface, $E_{\mathrm{sp}}$ values in winter are significantly higher (four times) in the center of the sea than on the shelf. They are comparable to the values of $E_{\mathrm{sp}}$ on the shelf. At the same time, at $40 \mathrm{~m}$ depth $E_{\mathrm{sp}}$ values in the center of the sea are an order of magnitude higher (Fig. 6, b) than in the bottom layers of the shelf, which is apparently associated with the velocity decay due to the bottom friction.

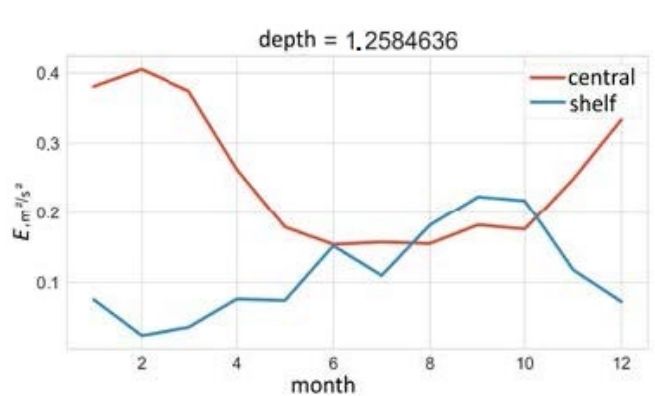

$a$

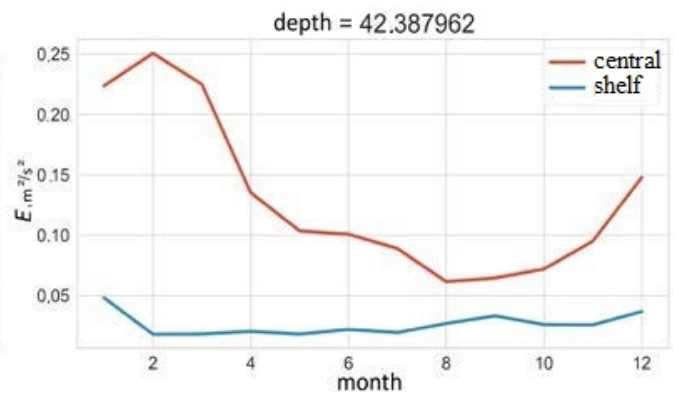

$b$

F i g. 6. Seasonal variability of the submesoscale currents spectral energy $(L<10 \mathrm{~km})$ in the central (red line) and shelf (blue line) parts of the Black Sea at $z=1 \mathrm{~m}(a)$ and at $z=43 \mathrm{~m}(b)$

The maximum $E_{\mathrm{sp}}$ in the center of the sea is observed in winter, in January - March. As shown in the vertical diagram in Fig. 7, $a$, at this time 
the highest intensity of submesoscale processes is observed throughout the ML. This distribution suggests that the instability of currents arising from the variability of MLD is an important reason for the formation of submesoscale eddies in the Black Sea, which is consistent with the data from the Atlantic Ocean [32, 33].

$E_{\text {sp }}$ in all seasons is maximum in the ML, the depth of which varies from 5-10 $\mathrm{m}$ in summer to $50 \mathrm{~m}$ in winter $[34,35]$. This relationship is also observed on an interannual scales. So, in cold 2008, when the UML was deeper, $E_{\text {sp }}$ penetrated to greater depths (50-60 m) (Fig. 9, a) than in the warmer 2009. The graph also indicates that $E_{\mathrm{sp}}$ variability is characterized by significant short-period fluctuations. Occasionally, a sharp increase in energy occurs in the entire mixed layer. A possible reason for such rise is an abrupt change in the MLD related to a sharp cooling or storm impact. Our more detailed analysis revealed that in summer in the center of the sea, the enhancement of submesoscale dynamics is also associated with the development of the Anatolian upwelling and baroclinic instability at its front, as well as the penetration of mesoscale eddies into the central part of the sea. A more detailed study of the short-period variability of $E_{\text {sp }}$ and its causes is planned in our future works.

The minimum $E_{\mathrm{sp}}$ in the center of the sea is observed in summer - autumn in the surface layers and in the autumn period (August - September) at $40 \mathrm{~m}$ depth. At this time, the peak of development of larger mesoscale eddies is observed in the Black Sea [36]. Despite the fact that at the periphery of these eddies, especially anticyclones, small submesoscale cyclones are often formed [30], in winter period we observed significantly more submesoscale eddies, related to the ML instabilities. Thus, in the central part of the Black Sea, the energy of submesoscale and mesoscale currents is in antiphase: submesoscale eddies intensify in winter, and mesoscale eddies in summer.

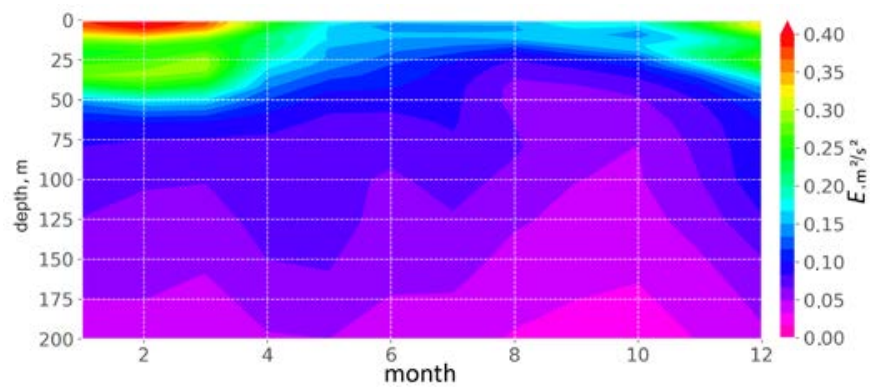

$a$

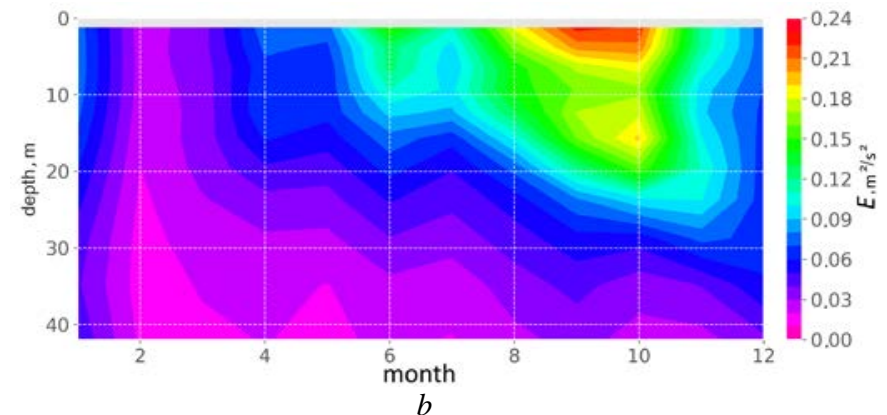

F i g. 7. Seasonal variability of the submesoscale currents spectral energy $(L<10 \mathrm{~km})$ in the central $(a)$ and shelf $(b)$ parts of the Black Sea 
The assumption about the importance of baroclinic instability is confirmed by the calculated spectral density variability on submesoscales for the studied regions of the Black Sea (Fig. 8). The diagrams of the seasonal variation of the vertical distribution of submesoscale variability of density and velocity are similar (Fig. 7). In winter, the maximum density fluctuations deepen to $50 \mathrm{~m}$ in the center of the sea, in summer - to $30 \mathrm{~m}$, which corresponds to the position of the seasonal thermocline. An increase in the submesoscale energy of the current velocity at the seasonal thermocline lower boundary $(20-30 \mathrm{~m})$ is also observed in summer according to the data presented in Fig. 7, $a$. However, these values are much lower than in winter. Intensification of large-scale circulation, wind impact, and intense buoyancy fluxes in winter are probably an important cause for the increase in submesoscale energy of currents and density fluctuations in winter compared to summer.

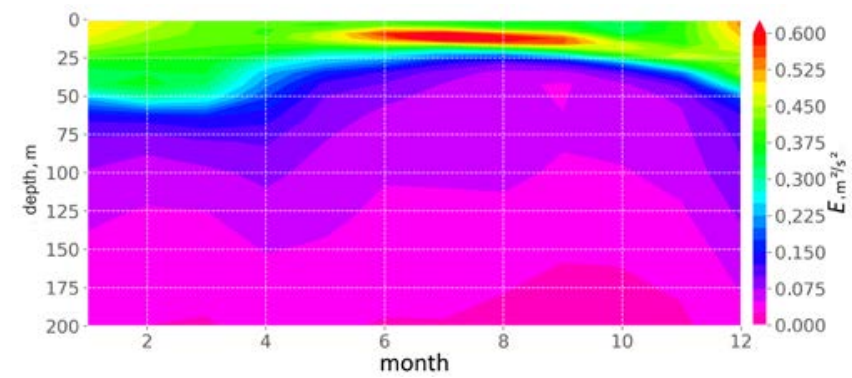

a

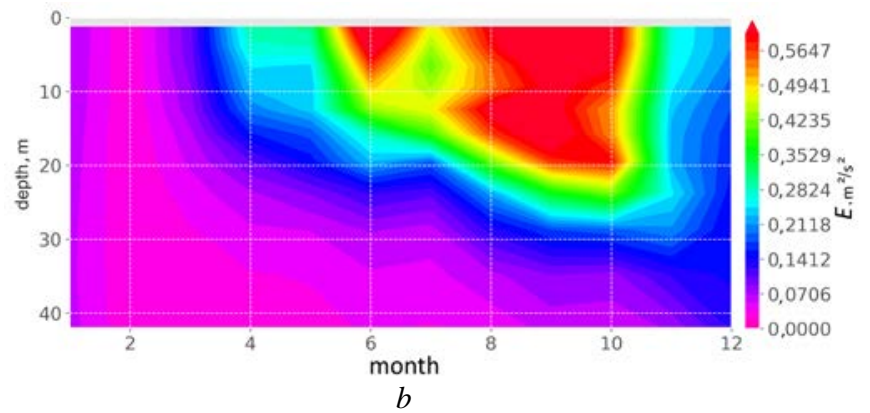

F i g. 8. Seasonal variability of the submesoscale density fluctuations $(L<10 \mathrm{~km})$ in the central $(a)$ and shelf_(b) parts of the Black Sea

On the contrary, in the shelf zone a sharp minimum of $E_{\mathrm{sp}}$ is observed in February. At this time, on the shelf, the water column is completely mixed. Due to the absence of density gradients, baroclinic currents on the shelf are absent, which leads to $E_{\mathrm{sp}}$ minimum in the entire water column. Such variability evidences about the important role of baroclinic motions and relatively low energy of barotropic currents on small spatial scales. This conclusion is also confirmed by a diagram of density fluctuations given in Fig. 8, $b$.

A significant increase in $E_{\mathrm{sp}}$ on the shelf is noted in August on the surface, and by September - October $E_{\mathrm{sp}}$ reaches a peak and its maximum values are traced to the greatest depths (Fig. $6, b ; 7, b$ ). An analysis of the numerical results revealed that the probable cause of such an increase is the advection of brackish riverine 
waters into the center of the shelf by the mesoscale eddies intensifying in summer [8]. An increase in the potential energy of waters, as well as a horizontal inhomogeneity of the salinity distribution, causes an intensive generation of baroclinic submesoscale eddies. An additional effect is provided by the barotropic instability caused by the velocity sheart at the periphery of mesoscale anticyclones $[15,16]$. The baroclinic instability at the lower boundary of the increasing ML can also make a contribution to $E_{\mathrm{sp}}$ in autumn. However, in December - January, when convection reach the bottom, water barotropization lead to the decrease of $E_{\mathrm{sp}}$. The graph of interannual variability shows that in winter of 2008 and $2009 E_{\text {sp }}$ decreased to minimum values in the entire water column. As well as in the center of the basin, $E_{\mathrm{sp}}$ is characterized by significant short-period fluctuations, the presence of sharp peaks and weakenings, especially noticeable in the autumn period. These events depend primarily on the penetration of river plume waters into this region, as well as on the passage of fronts associated with larger mesoscale eddies.

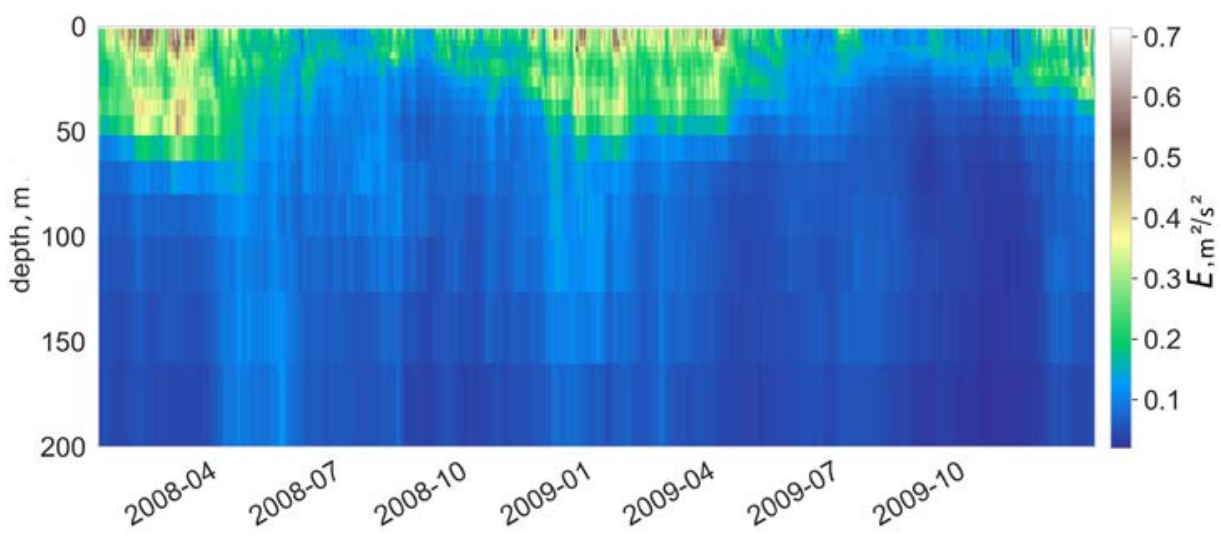

$a$

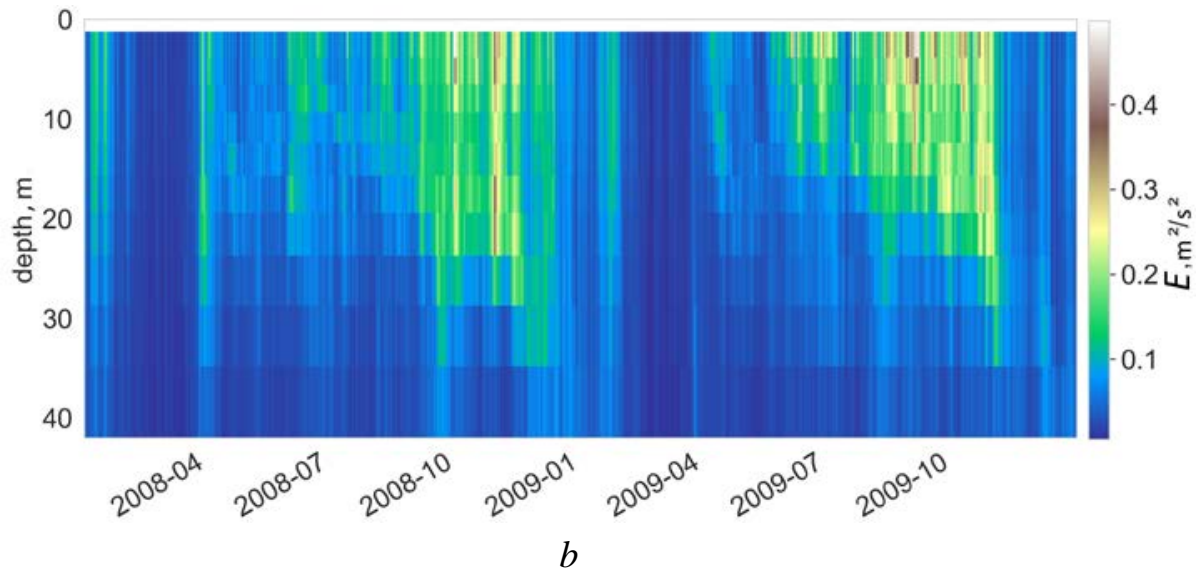

F i g. 9. Interannual variability of the submesoscale currents energy $(L<10 \mathrm{~km})$ in the central $(a)$ and shelf_(b) parts of the Black Sea 


\section{Conclusion}

In this work, based on the results of numerical modeling of NEMO model with a high spatial resolution of $1 \mathrm{~km}$, the study of the seasonal and vertical variability of submesoscale currents in the central and shelf parts of the Black Sea is carried out for the first time.

The highest values of spectral energy of submesoscale currents $E_{\mathrm{sp}}$ in the central part of the sea are concentrated in the ML. In winter, with an increase of the MLD, a seasonal $E_{\mathrm{sp}}$ peak is observed in the 0-40 m layer; in summer, relatively high values are observed in the upper $(0-20 \mathrm{~m}) \mathrm{ML}$ and seasonal thermocline. Such seasonal variability evidences about decisive role of baroclinic instability, arising from the heterogeneity of the ML [8], in the generation of submesoscale processes in the Black Sea central part. This is also supported by a significant similarity in the variability of the spectral energy of density and velocity fluctuations in the studied regions.

At the same time, in deep 50-250 m layers high $E_{\text {sp }}$ values are observed in April - May (Fig. 5), which is possibly due to the generation of intense anticyclones during this period, the shear instability at the periphery of which leads to the formation of submesoscale eddies [18, 32] under the main pycnocline.

The submesoscale energy in the shelf zone central part is lower than in the center of the sea and has a completely different seasonal variability. The maximum $E_{\mathrm{sp}}$ values are observed in August - October with a peak in October. The main cause for this autumn maximum is the advection of brackish riverine waters into the center of the NWS under the effect of mesoscale eddies intensifying during this period. The resulting salinity gradients, as well as barotropic shear instability, lead to the generation of intense baroclinic submesoscale eddies. The vertical extent of the region of high $E_{\mathrm{sp}}$ values increases from August to January, which coincides with the dynamics of the MLD. In February, a minimum of $E_{\mathrm{sp}}$ is noted along with the entire depth, associated with the water column barotropization due to complete winter convective mixing.

The variability of submesoscale dynamics energy is of a pulsating nature with short-term intensifications and weakenings. They are associated with the passage of mesoscale fronts and cross-shelf water transport caused by eddies and upwellings, and the effect of intense storms and cooling.

\section{REFERENCES}

1. McWilliams, J.C., 2016. Submesoscale Currents in the Ocean. Proceedings of the Royal Society A. Mathematical, Physical and Engineering Sciences, 472(2189), 20160117. doi:10.1098/rspa.2016.0117

2. Klein, P. and Lapeyre, G., 2009. The Oceanic Vertical Pump Induced by Mesoscale and Submesoscale Turbulence. Annual Review of Marine Science, 1, pp. 351-375. doi:10.1146/annurev.marine.010908.163704

3. Capet, X., Mcwilliams, J.C., Molemaker, M.J. and Shchepetkin, A.F., 2008. Mesoscale to Submesoscale Transition in the California Current System. Part II: Frontal Processes. Journal of Physical Oceanography, 38(1), pp. 44-64. https://doi.org/10.1175/2007JPO3672.1

4. Thomas, L.N., Tandon, A. and Mahadevan, A., 2008. Submesoscale Processes and Dynamics. In: M. W. Hecht and H. Hasumi, Eds., 2008. Ocean Modeling in an Eddying Regime. Washington, D. C.: American Geophysical Union, pp. 17-38. doi:10.1029/177GM04 
5. Mahadevan, A. and Tandon, A., 2006. An Analysis of Mechanisms for Submesoscale Vertical Motion at Ocean Fronts. Ocean Modelling, 14(3-4), pp. 241-256. doi:10.1016/j.ocemod.2006.05.006

6. Aleskerova, A.A., Kubryakov, A.A., Goryachkin, Yu.N. and Stanichny, S.V., 2017. Propagation of Waters from the Kerch Strait in the Black Sea. Physical Oceanography, (6), pp. 47-57. doi:10.22449/1573-160X-2017-6-47-57

7. Aleskerova, A.A., Kubryakov, A.A., Goryachkin, Y.N., Stanichny, S.V. and Garmashov, A.V., 2019. Distribution of Suspended Matter off the Western Coast of the Crimea under Impact of the Strong Winds of Various Directions. Issledovaniye Zemli iz Kosmosa, (2), pp. 74-88. doi:10.31857/S0205-96142019274-88 (in Russian).

8. Kubryakov, A.A., Stanichny, S.V. and Zatsepin, A.G., 2018. Interannual Variability of Danube Waters Propagation in Summer Period of 1992-2015 and Its Influence on the Black Sea Ecosystem. Journal of Marine Systems, 179, pp. 10-30. doi:10.1016/j.jmarsys.2017.11.001

9. Zatsepin, A., Kubryakov, A., Aleskerova, A., Elkin, D. and Kukleva, O., 2019. Physical Mechanisms of Submesoscale Eddies Generation: Evidences from Laboratory Modeling and Satellite Data in the Black Sea. Ocean Dynamics, 69(2), pp. 253-266. doi:10.1007/s10236018-1239-4

10. Lavrova, O.Yu. and Bocharova, T.Yu., 2006. Satellite SAR Observations of Atmospheric and Oceanic Vortex Structures in the Black Sea Coastal Zone. Advances in Space Research, 38(10), pp. 2162-2168. doi:10.1016/j.asr.2006.03.022

11. Luo, H., Bracco, A., Cardona, Y. and McWilliams, J.C., 2016. Submesoscale Circulation in the Northern Gulf of Mexico: Surface Processes and the Impact of the Freshwater River Input. Ocean Modelling, 101, pp. 68-82. doi:10.1016/j.ocemod.2016.03.003

12. Lavrova, O., Serebryany, A., Bocharova, T. and Mityagina, M., 2012. Investigation of fine Spatial Structure of Currents and Submesoscale Eddies Based on Satellite Radar Data and Concurrent Acoustic Measurements. Proceedings of SPIE, Remote Sensing of the Ocean, Sea Ice, Coastal Waters, and Large Water Regions, 8532, 85320L. doi:10.1117/12.970482

13. Karimova, S.S., Lavrova, O.Yu. and Solov'ev, D.M., 2012. Observation of Eddy Structures in the Baltic Sea with the Use of Radiolocation and Radiometric Satellite Data. Izvestiya, Atmospheric and Oceanic Physics, 48(9), pp. 1006-1013. doi:10.1134/S0001433812090071

14. Aleskerova, A.A., Kubrjakov, A.A. and Stanichny, S.V., 2015. Propagation of Suspended Matter under the Influence of Storm Winds off the Western Coast of Crimea by HighResolution Optical Data. Sovremennyye Problemy Distantsionnogo Zondirovaniya Zemli iz Kosmosa, 12(1), pp. 63-71 (in Russian).

15. Zatsepin, A.G., Baranov, V.I., Kondrashov, A.A., Korzh, A.O., Kremenetskiy, V.V., Ostrovskii, A.G. and Soloviev, D.M., 2011. Submesoscale Eddies at the Caucasus Black Sea Shelf and the Mechanisms of Their Generation. Oceanology, 51(4), 554. doi:10.1134/S0001437011040205

16. Zatsepin, A., Kubryakov, A., Aleskerova, A., Elkin, D. and Kukleva, O., 2019. Physical Mechanisms of Submesoscale Eddies Generation: Evidences from Laboratory Modeling and Satellite Data in the Black Sea. Ocean Dynamics, 69(2), pp. 253-266. doi:10.1007/s10236018-1239-4

17. Shcherbina, A.Y., D'Asaro, E.A., Lee, C.M., Klymak, J.M., Molemaker, M.J. and McWilliams, J.C., 2013. Statistics of Vertical Vorticity, Divergence, and Strain in a Developed Submesoscale Turbulence Field. Geophysical Research Letters, 40(17), pp. 47064711. doi:10.1002/grl.50919

18. Brannigan, L., Marshall, D.P., Naveira-Garabato, A. and Nurser, A.J.G., 2015. The Seasonal Cycle of Submesoscale Flows. Ocean Modelling, 92, pp. 69-84. doi:10.1016/j.ocemod.2015.05.002

19. Callies, J., Ferrari, R., Klymak, J. and Gula, J., 2015. Seasonality in Submesoscale Turbulence. Nature Communications, 6, 6862. doi:10.1038/ncomms7862 
20. Mensa, J.A., Garraffo, Z., Griffa, A., Özgökmen, T.M., Haza, A. and Veneziani, M., 2013. Seasonality of the Submesoscale Dynamics in the Gulf Stream Region. Ocean Dynamics, 63(8), pp. 923-941. doi:10.1007/s10236-013-0633-1

21. Thompson, A.F., Lazar, A., Buckingham, C., Naveira Garabato, A.C., Damerell, G.M. and Heywood, K.J., 2016. Open-Ocean Submesoscale Motions: A Full Seasonal Cycle of Mixed Layer Instabilities from Gliders. Journal of Physical Oceanography, 46(4), pp. 1285-1307. doi:10.1175/JPO-D-15-0170.1

22. Demyshev, S.G. and Dymova, O.A., 2013. Numerical Analysis of the Mesoscale Features of Circulation in the Black Sea Coastal Zone. Izvestiya, Atmospheric and Oceanic Physics, 49(6), pp. 603-610. https://doi.org/10.1134/S0001433813060030

23. Divinsky, B.V, Kuklev, S.B., Zatsepin, A.G. and Chubarenko, B.V, 2015. Simulation of Submesoscale Variability of Currents in the Black Sea Coastal Zone. Oceanology, 55(6), pp. 814-819. https://doi.org/10.1134/S000143701506003X

24. Zalesnyi, V.B., Gusev, A.V. and Agoshkov, VI, 2016. Modeling Black Sea Circulation with High Resolution in the Coastal Zone. Izvestiya, Atmospheric and Oceanic Physics, 52(3), pp. 277-293. https://doi.org/10.1134/S0001433816030142

25. Madec, G., 2008. NEMO Ocean Engine. Note du Pôle de modélisation. France: Institut Pierre-Simon Laplace. Available at: https://www.nemo-ocean.eu/doc/node1.html [Accessed: 5 November 2020].

26. Mizyuk, A.I., Korotaev, G.K., Grigoriev, A.V., Puzina, O.S. and Lishaev, P.N., 2019. Long-Term Variability of Thermohaline Characteristics of the Azov Sea Based on the Numerical Eddy-Resolving Model. Physical Oceanography, 26(5), pp. 438-450. doi:10.22449/1573-160X-2019-5-438-450

27. Zalesak, S.T., 1979. Fully Multidimensional Flux-Corrected Transport Algorithms for Fluids. Journal of Computational Physics, 31(3), pp. 335-362. https://doi.org/10.1016/00219991(79)90051-2

28. Rodi, W., 1987. Examples of Calculation Methods for Flow and Mixing in Stratified Fluids. Journal of Geophysical Research: Oceans, 92(C5), pp. 5305-5328. https://doi.org/10.1029/JC092iC05p05305

29. Zatsepin, A.G., Ginzburg, A.I., Kostianoy, A.G., Kremenetskiy, V.V., Krivosheya, V.G., Stanichny, S.V. and Poulain, P.-M., 2003. Observations of Black Sea Mesoscale Eddies and Associated Horizontal Mixing. Journal of Geophysical Research: Oceans, 108(C8), 3246. doi:10.1029/2002JC001390

30. Kubryakov, A.A. and Stanichny, S.V., 2015. Seasonal and Interannual Variability of the Black Sea Eddies and Its Dependence on Characteristics of the Large-Scale Circulation. Deep Sea Research Part I: Oceanographic Research Papers, 97, pp. 80-91. doi:10.1016/j.dsr.2014.12.002

31. Nelepo, B. A., Ed., 1984. Variability of Hydrophysical Fields of the Black Sea. Leningrad: Gidrometeoizdat, 240 p. (in Russian).

32. Callies, J., Flierl, G., Ferrari, R. and Fox-Kemper, B., 2016. The Role of Mixed-Layer Instabilities in Submesoscale Turbulence. Journal of Fluid Mechanics, 788, pp. 5-41. doi:10.1017/jfm.2015.700

33. Titov, V.B., 2004. Integral Effect of Thermal and Dynamical Atmospheric Factors on the Hydrological Structure of the Black Sea Waters. Oceanology, 44(6), pp. 783-788.

34. Kubryakov, A.A., Belokopytov, V.N., Zatsepin, A.G., Stanichny, S.V. and Piotukh, V.B., 2019. The Black Sea Mixed Layer Depth Variability and Its Relation to the Basin Dynamics and Atmospheric Forcing. Physical Oceanography, 26(5), pp. 397-413. doi:10.22449/1573160X-2019-5-397-413

35. Kubryakov, A.A., Mizyuk, A.I., Puzina, O.S. and Senderov, M.V., 2018. ThreeDimensional Identification of the Black Sea Mesoscale Eddies according to NEMO Numerical Model Calculations. Physical Oceanography, 25(1), pp. 18-26. doi:10.22449/1573-160X-2018-1-18-26 
About the authors:

Oksana S. Puzina, Junior Research Associate, Marine Hydrophysical Institute of RAS (2 Kapitanskaya str., Sevastopol, 299011, Russian Federation), ORCID ID: 0000-0002-1637-4475, oksana_puzina@mhi-ras.ru

Arseniy A. Kubryakov, Senior Research Associate, Marine Hydrophysical Institute of RAS (2 Kapitanskaya str., Sevastopol, 299011, Russian Federation), Ph. D. (Phys.-Math.), ORCID ID: 0000-0003-3561-5913, arskubr@mhiras.ru

Artem I. Mizyuk, Senior Research Associate, Marine Hydrophysical Institute of RAS (2 Kapitanskaya str., Sevastopol, 299011, Russian Federation), Ph. D. (Phys.-Math.), ORCID ID:0000-0003-4885-354X, ResearcherID: C-6125-2016, artem.mizuk@mhi-ras.ru

Contribution of the co-authors:

Oksana S. Puzina - calculations and analysis, generalization of research results, interpretation of research results, text writing, manuscript design, work with graphic material, the manuscript editing and revision

Arseniy A. Kubryakov - concept and research plan, guidance in writing the paper, formulation of conclusions, analysis and synthesis of literature data, collection of literature data; text writing

Artem I. Mizyuk - carrying out the numerical simulations, text writing, critical revision of the text content

All the authors have read and approved the final manuscript.

The authors declare that they have no conflict of interest. 